\title{
GUMRAH WEWARAH
}

\author{
Oleh : Yuni Ratnasari \\ (Pembimbing Tugas Akhir Dra. Daruni, M.Hum dan Drs. Y Subowo, M.Sn.) \\ Jurusan Seni Tari, Fakultas Seni Pertunjukan Istitut Seni Indonesia Yogyakarta \\ Jl. Parangtritis km. 6,5Sewon, Bantul, Yogyakarta \\ Email: moon_uneyratna@yahoo.com (087739396196)
}

\section{RINGKASAN}

Karya tari tugas akhir berjudul Gumrah Wewarah terinspirasi oleh salah satu punokawan putri yakni tokoh Limbuk. Gumrah Wewarah, Gumrah memiliki arti ramai, keramaian, dan bercanda yang berkonotasi positif, sedangkan Wewarah memiliki arti nasehat. Gumrah Wewarah bercerita tentang perjalanan hidup Bathari Kanestren yang berubah wujud menjadi Limbuk, ia selalu memberikan suasana yang bahagia, sumringah, ramai dan selalu jenaka, memiliki tujuan agar yang di momong betah, remaket dan bahagia namun dibalik kelucuannya ada nasehat yang tersirat didalamnya. Mulut Limbuk yang mengucap dan mengurai sebuah makna tentang kesejatian perempuan nuswantara yang terpilih, dan semua ucapan dan uraian itu selalu disampaikan lewat mulut yang tersenyum.

Limbuk adalah pamomong yang tergolong masih remaja berkarakter genit namun selalu memberikan tuntunan dan memuat wewarah didalam kejenakaannya, ia selalu membawa cermin, sisir dan kacu yang menjadi identitasnya, alat-alat tersebut digunakan untuk menghias dirinya sendiri ataupun mendandani para putri yang di emong nya.

Karya tari divisualisasikan dalam komposisi tari kelompok, didukung oleh tujuh penari putri, putri menggambarkan tokoh Limbuk yang berjenis kelamin wanita, selain itu memberikan pitutur tentang bagaimana seharusnya wanita bersikap, keanggunan dan peranan wanita yang begitu penting di kehidupan ini. Tujuh penari sebagai simbol pitulungan. Karya ini dipentaskan di proscenium stage. Pijakan pengembangan gerak berasal dari gerak tari putri gaya yogyakarta terutama motif gerak kiprah sekaran gecul, merak ngigel, lilingan, dan encot.

Kata Kunci: Karya Tari, Gumrah Wewarah, Limbuk, Pamomong.

\section{ABSTRACT}

The dance for the final project named Gumerah Wewarah inspired by one of the punakawan called limbuk. Gumrah Wewarah, Gumrah means cheerful and comical in positive ways, while wewarah means advice. Gumrah Wewarah tells the story of Bathari Kanestren who transformed became a limbuk. She is a woman who is very cheerful and comical. She always brings happiness to the people around her. When she takes care of princesses, she always delivers advice in comical ways. The mouth of limbuk delivers a meaning of the genuineness women of Nuswantara, moreover all speech and advice always delivered through smiling mouth.

Although Limbuk is a teenager nanny who is girlish, she always delivers advice in comical ways. She always carries a mirror, combs, and handkerchief which are her identity. Those stuffs are used to help her in grooming. 
The dance is performed in a dance group. It supported by seven girl dancers. The girl dancers represent the limbuk who is a woman. Moreover, they give the good examples of the women's behavior. They portray elegance and the role of women who are very important in this life. The seven dancers symbolized a help. This dance had performed in proscenium stage. The basic movements are the style from Yogyakarta, especially the movements such as kiprah sekaran gecul, merak ngigel, lilingan, and encot.

Key Words: Karya Tari, Gumrah Wewarah, Limbuk, Pamomong.

\section{PENDAHULUAN}

Tokoh Wayang selalu menarik untuk diketahui, karena selalu memiliki keunikankeunikan yang sangat menarik untuk dipelajari lebih jauh dari hanya sekedar tahu. Wayang Purwa, Wayang Madya, maupun jenis Wayang yang lainnya dengan karakter masing-masing. Kadang satu tokoh hadir pada setiap zaman, tapi ada pula yang hanya sekali di zaman tertentu. Sebagai contoh adalah Punokawan. Punokawan selalu hadir pada setiap jaman dalam Pewayangan. Dalam buku Ensiklopedi Wayang disebutkan bahwa mereka ada dari sebelum zaman Kerajaan Lokapala, sampai setelah era Hastinapura surut, mereka selalu hadir menjadi pamomong sekaligus emban yang bertugas mengasuh, menghibur, menasehati, dan menjaga keselamatan seorang putra atau putri raja sejak kanak kanak. Mereka juga memiliki sebutan atau julukan yang berbeda beda atau dalam bahasa Jawa disebut Dasanama. (Sena Wangi, Ensiklopedi Wayang Indonesia 1, Jakarta : Sena Wangi, 1999, p.259)

Punokawan secara karakteristik sebenarnya mewakili profil umum manusia. Mereka adalah tokoh multi-peran yang dapat menjadi penasihat para penguasa atau satria bahkan dewa. Mereka juga berperan sebagai penghibur, kritikus, sekaligus menjadi penyampai kebenaran, kebajikan dan penganjur keutamaan. Dari mereka kita dapat mengambil banyak hikmah. Dibalik wujudnya yang kurang proporsional dan sosok yang sederhana, namun memiliki kedalaman ilmu yang luar biasa. Para dewa pun tidak ada yang berani marah, cara penyampaiannya dalam memberi pesan-pesan bermakna secara jenaka dengan ungkapan yang polos, ceplas-ceplos tetapi jujur atau sering disebut parikeno.

Punokawan yang sering dikenal ada 4 tokoh yaitu Semar, Gareng, Petruk, dan Bagong, namun masih ada tokoh-tokoh yang termasuk kategori Punokawan atau sosok yang bertugas sebagai pamomong para Raja atau Ksatria. Mereka adalah Togog dan Bilung. Mereka bertugas mendampingi Raja atau Satria berwatak jahat. Ada juga Punokawan perempuan, mereka adalah Limbuk dan Cangik. Dari delapan tokoh pewayangan yang termasuk kategori Punokawan ini memiliki bentuk, rupa dan karakter yang berbeda-beda. Wujud mereka cenderung jenaka. Salah satu tokoh yang menarik perhatian penata untuk diambil dan diangkat dalam garapan tari adalah tokoh punokawan putri yaitu Limbuk.

Limbuk tidak pernah lepas dari tokoh Cangik, ada Limbuk, pasti ada Cangik. Walau demikian, garapan ini tetap memfokuskan pada satu sosok yaitu Limbuk. Sosok tersebut menjadi sumber inspirasi garapan dan akan dicari kemungkinan-kemungkinan yang bisa dihadirkan. Penata terinspirasi dari tokoh Limbuk, sosok Limbuk tidak hanya dilihat dari sisi kejenakaan, serta karakter lain yang melekat pada sosok Limbuk pada umumnya. Tetapi tokoh tersebut akan dikupas lebih dalam sehingga di samping terasa segar, karya ini diharapkan akan mengandung bobot serta kedalaman.

Tokoh Limbuk sudah sangat populer di mata masyarakat. Tokoh ini dikenal sebagai tokoh pamomong dalam pewayangan. Biasanya tokoh Limbuk yang selalu hadir dalam pertunjukan wayang kulit pada adegan 
Limbukan atau sering disebut adegan Gumpit Mandragini yakni adegan yang terletak sebelum goro-goro, atau sebelum adegan perang gagal. Tokoh-tokoh dalam adegan Limbukan bisa berdialog tentang apa saja dengan bebas, tidak terikat pakem, dengan bahasa yang populer dan juga komunikatif. ( Wawancara Mas Panewu Cermo Sutedjo, 28 Oktober 2015 di Gedong Kuning, diijinkan untuk dikutip). Ia dihadirkan sebagai penghibur penonton pertunjukan Wayang Kulit yang sebelumnya menghadirkan adegan konflik dengan suasana tegang. Tujuannya membuat dinamika pertunjukan agar terasa cair atau fresh serta memberi pesan-pesan yang dapat tersampaikan secara tidak terasa dan diharapkan agar didengar, dipatuhi atau diikuti oleh penontonnya. Pada adegan Limbukan juga menceritakan bagaimana perempuan diposisikan dan diharapkan bertingkah laku dalam masyarakat Jawa pada umumnya, juga mengandung tuntutan kepantasan, norma atau nilai masyarakat Jawa terhadap kepantasan perempuan. Limbuk tidak pernah terpisahkan dengan tokoh Cangik. Keduanya merupakan abdi dalem emban Punokawan Putri Keraton yang memiliki tugas melayani, menghibur, mengasuh, menjaga keselamatan dan menjadi pamomong para putri atau ratu di keputren, secara spiritual mendidik dan membentuk moral, karakter, sifat momongannya agar menjadi sosok pemimpin yang Sekarjati. Kedua tokoh tersebut memiliki rupa atau bentuk yang Jenaka dan lucu.

Limbuk digambarkan sebagai abdi yang masih remaja atau gadis sehingga ia sangat peduli dan fokus dengan penampilannya sendiri maupun penampilan momongannya. Salah satu keingina Limbuk yang sangat besar adalah keinginan untuk menikah yang memiliki makna bahwa perempuan adalah lambang kehormatan, kekuasaan dan harga diri laki-laki yang harus dicari dan dipertahankan dan apabila ada yang mengusiknya maka nyawalah taruhannya karena sesungguhnya perempuan adalah wanita penting yang kanggonan wahyu dan dianggap етри oleh laki-laki. Pada konsep hidup orang Jawa ketika seseorang sudah menikah maka hidupnya sudah sempurna.

Secara postur tubuh Limbuk berbadan subur atau gemuk memiliki makna bahwa manusia memiliki kelebihan masing-masing, Limbuk memiliki kepercayaan diri yang tinggi dan suaranya yang keras, besar dan mblewer seperti laki-laki diikuti dengan keletahnya, hidungnya pesek, dahinya lebar, bermata keran, hidung kepik, sanggul gedhe dikembangi, setiap ia berjalan, selalu diiringi alat musik kendang yang menjadi iringan khas seorang yang berbadan besar, memiliki karakter genit dan selalu berhias, tak pernah ketinggalan membawa sisir, cermin dan kacu. Sedangkan Cangik memiliki tubuh kurus. Orang mengenal tokoh Limbuk dan Cangik sebagai sosok yang jenaka dan suka bercanda namun di setiap tindakan dan perilakunya yang jenaka memiliki petuah dan makna dibaliknya. Ada dalang yang memberikan gambaran bahwa hubungan Limbuk dan Cangik hanyalah rekan satu pekerjaan, namun sebagian besar dalang menyebutkan Limbuk adalah anak Cangik. ( Sena Wangi, Ensiklopedi wayang. 1991, p.151).

Dalam suatu kepercayaan masyarakat di Jawa yang sering disebut dengan kejawen, hal tersebut dituliskan dalam jurnal yang berjudul Jagad Gumelar yang menyatakan bahwa Limbuk dianggap bukan sekedar sebagai pamomong dalam konteks abdi, tetapi ia dipercaya sebagai salah satu Pamong Nuswantara. Masyarakat tertentu percaya bahwa Limbuk adalah wujud nyata yang bisa menampakkan diri kapanpun ia mau. Ia dipercaya sebagai wujud pamong dari Batari Kanestren isteri Batara Ismaya yang wujud pamongnya adalah Ki Lurah Semar (Timmy Hartadi dan Agung Bimo Sutedjo, Jagad Gumelar, Tatanan Jagad Raya, Yogyakarta: Turanggaseta, 2009, p.20). Bersama Nyi Cangik, ia dipercaya mengawal Wahyu Putri yang bernama Wahyu Prajna Paramitha. Saat ini ia dipercaya menduduki wilayah pantai selatan bersama Kanjeng Ratu Kidul. 
( Wawancara Timmy Hartadi, 2 November 2015 di Tuntungan, diijinkan untuk dikutip)

Hal tersebut diatas menginspirasi penata untuk menumbuhkan ide yang kemudian dirancang dan diwujudkan ke dalam garapan tari. Karya ini mengangkat tokoh Limbuk yang mengacu dari berbagai sumber, antara lain versi Pedalangan, tinjauan Filosofi, serta versi Kejawen yang sangat percaya akan keberadaan Limbuk itu sendiri. Beberapa versi diambil, diolah menjadi satu kesatuan yang saling melengkapi dan saling menguatkan kedalam sebuah garapan tari berjudul Gumrah Wewarah ini.

Karya tari berjudul Gumrah Wewarah ini mengangkat tema tentang keteladanan Limbuk, baik saat sebagai Batari Kanestren yang merupakan sosok ibu Jagad yang baik hati dan pengasih sampai berubah ke wujud Limbuk sebagai pamong putri Nuswantara yang selalu sumringah dan jenaka. Pamomong yang selalu memberikan arahan, petuah serta tuntunan lewat pendekatan Kawruh (pengetahuan kasat mata), pendekatan ngelmu (pengetahuan tidak kasat mata) dan pendekatan ngelmi (pengetahuan yang bersumber dari religiusitas) yang bertujuan untuk menjadikan putri yang diemong menjadi putri yang Sekarjati (Bunga yang sejati) setiap kata yang terucap selalu disampaikan dengan mulut yang tersenyum (esem). ( Daruni, "Limbuk Cangik sebagai Inspirasi Perancangan Koreografi Duet Sih Biyung", dalam Resital Jurnal Seni Pertunjukan Volume 14 No. 2 - Desember. Yogyakarta: Fakultas Seni Pertunjukan Institut Seni Indonesia Yogyakarta, 2013, p. 162)

Karya tari dalam bentuk koreografi kelompok ini tidak menggunakan tema dan konsep komikal atau gecul tetapi apabila ada kesan lucu dan gecul itu hanyalah efek dari karakter tokoh Limbuk yang jenaka dan efek dari bentuk tubuh yang tidak proporsional. Gerak nantinya akan berdasarkan pengembangan gerak tari putri gaya Yogyakarta yaitu motif encot, ngleyek, ombak banyu, untuk menggambarkan saat menjadi Batari sedangkan saat menjadi Limbuk menggunakan gerak hasil dari eksplorasi motif gerak kiprah sekaran gecul, merak ngigel, lilingan, dan encot serta eksplorasi properti seperti sisir, cermin dan kacu.

\section{PEMBAHASAN}

\section{A. Kerangka Dasar Penciptaan}

Karya tari Gumrah Wewarah yang telah dipentaskan pada tanggal 21 dan 22 Januari 2016 di proscenium stage Jurusan Tari Fakultas Seni Pertunjukan Institut Seni Indonesia Yogyakarta. Penciptaan karya tari ini terinspirasi dari tokoh Limbuk dari berbagai versi. Informasi dari para nara sumber, serta ketertarikan penata pada sosok serta asal-usul tokoh Limbuk yang belum banyak diketahui orang menjadi sumber inspirasi ide atau gagasan. Dengan kata lain rangsang tari berawal dari rangsang visual kemudian berkembang menjadi rangsang idesional yang membuat terciptalah karya Gumrah Wewarah. Gumrah Wewarah, terinspirasi oleh salah satu punokawan putri yakni tokoh Limbuk. Gumrah memiliki arti ramai, keramaian, dan bercanda yang berkonotasi positif, sedangkan Wewarah memiliki arti nasehat. Gumrah Wewarah mewakili sebuah kisah tentang sosok seorang Bathari Kanestren yang telah berubah wujud menjadi Limbuk. Tema yang diambil tentang keteladanan Limbuk, yang disajikan dengan bentuk studi dramatik, diungkapkan dengan cara simbolik representasional.

Gerak-gerak tari yang digunakan dalam karya ini adalah pengembangan gerak tari putri gaya Yogyakarya dan pengembangan dari kiprah sekaran gecul, merak ngigel, lilingan, dan encot, serta eksplorasi properti seperti sisir, cermin dan kacu. Karya tari ini tidak dapat lepas dari ketiga properti tersebut karena ketiga properti tersebut merupakan identitas Limbuk, baik saat ia menjadi Batari maupun sudah berwujud Limbuk. Ketiga properti tersebut sebagai media untuk memberikan tuntunan kepada momongannya. Cermin atau pengilon memiliki makna berkaca diri, bahwa manusia harus selalu introspeksi kapanpun dan 
dimanapun. Sisir memiliki makna menata dan menjaga mahkota serta kehormatan apalagi bagi wanita. Sedangkan kacu memiliki arti membuang hal-hal negatif yang ada di dalam diri manusia.

Karya tari ini ditarikan oleh tujuh orang perempuan. Tujuh sebagai penggambaran tujuh fase kehidupan manusia yang dilalui hingga mencapai kesempurnaan dalam hidup khususnya yang di rasakan oleh perempuan, serta tujuh yang berarti pitulungan merupakan salah satu fungsi pamomong. Penata memilih penari perempuan dikarenakan tokoh dan alur cerita yang diambil adalah tentang perempuan, dari penggambaran Batari Kanestren, Limbuk hingga semua nasehat yang ada pada Limbuk adalah diperuntukkan untuk perempuan. Satu perempuan lagi sebagai penggambaran Wahyu Pradja Paramitha.

Musik karya ini menggunakan musik play back dengan format Musical Instrument Digital Interface (MIDI) yang diformulasikan dalam bentuk wafeform audio file. Selain itu memiliki tujuan lain untuk menghemat biaya selama proses latihan serta untuk mempermudah proses latihan antara penari dan musik. Musik yang digunakan pada karya Gumrah Wewarah ini berpijak pada gendhinggendhing Jawa seperti kemanak, ladrang, ayak-ayak, juga memasukan gaya parikan agar lebih komunikatif. Menggunakan juga gaya cakepan wangsalan. Cakepan wangsalan ialah sejenis syair tembang dalam gamelan yang berisi pantun dengan isi petuah kehidupan. Pada adegan introduksi menggunakan dasar lagon plencung jugag atau suluk (tembang dalang yang kemudian di kembangkan sedemikian rupa). Suluk ini menceritakan tentang kecantikan wanita dari lahir hingga batin. Selain itu juga memasukan unsur-unsur mantra Jawa yang digunakan untuk berdoa atau memulai memohon keselamatan.

Rias yang digunakan dalam tari "Gumrah Wewarah" berupa rias korektif cantik untuk penggambaran Bathari Kanestren. Busana yang digunakan saat menjadi Kanestren yaitu kemben berwarna merah muda dan rok wiron berwarna ungu, kemudian saat memerankan Limbuk rias tetap cantik tetapi ditambah aksen lipstik dan blush on yang tebal agar terlihat cantik menor dan penambahan kostum untuk bagian payudara dan pantat palsu agar penari terlihat gemuk saat menjadi Limbuk. Busana yang digunakan kemben bermotif lurik dan jarik berwarna hijau yang diberi motif kawung pada bagian bawah jarik.Saat menjadi Kanestren hair do yang digunakan adalah sanggul kreasi yang diberi asesoris kepala berupa mahkota dan menggunakan sumping. Saat menjadi Limbuk menggunakan sanggul dan sisir serta asesoris kepala yang berbentuk seperti sumping.

Konsep pencahayan yang digunakan yaitu, pada adegan intro menggunakan focus on two point, menggunakan lampu yang berwarna kuning untuk menggambarkan keagungan sosok pamomong dan Wahyu Pradja Paramitha. Pada adegan satu menggunakan lampu berwarna biru yang menggambarkan suasana mistis di khayangan, kemudian menggunakan warna lampu merah muda untuk menggambarkan Bhatari yang masih remaja. Pada adegan dua menggunakan lampu general berwarna kuning untuk menggambarkan kebahagiaan Limbuk turun ke bumi untuk melaksanakan tugasnya. Adegan tiga menggunakan focus on three point, yang masing-masing membawa tiga properti yang berbeda-beda. Warna lampu yang digunakan percampuran antara warna biru, warna kuning dan warna merah untuk menggambarkan keseriusan Limbuk dalam melaksanaka tugasnhya. Sedangkan saat ending menggunakan lampu disorotkan dari belakang salah satu penari untuk memberikan kesan agung. Tata suara yang baik juga dibutuhkan karena mengingat musik yang dipilih adalah MIDI sehingga sangat membutuhkan sound yang bagus. Adapun Sound yang dibutuhkan adalah Stereo PA system, menggunakan power 5000 watt, speaker 3 way system, Monitoring system menggunakan 4 speaker dan mixer 2 channel. 


\section{B. Metode dan Tahapan Penciptaan}

1. Metode yang ditempuh penata dalam menciptakan tari Gumrah Wewarah ini adalah sebagai berikut:

\section{a. Eksplorasi}

Eksplorasi adalah suatu penjajagan terhadap objek atau fenomena dari luar dirinya; suatu pengalaman untuk mendapatkan rangsangan, sehingga dapat memperkuat daya kreativitas (Y. Sumandiyo Hadi, Koreografi Bentuk-Teknik-Isi, Yogyakarta: Cipta Media, 2012, p. 70). Eksplorasi juga berarti penjelajahan atau pencarian. Bermula dari kekaguman akan sosok Limbuk yang selalu hadir di acara Wayangan yang mampu mencairkan suasana dan selalu mengurai nasehat dengan gaya Parikeno nya. Gerakannya yang unik yang menjadi ciri khasnya membuat penata ingin mengeksplor lebih jauh. Penata melakukan pengamatan secara langsung yang berawal dari melihat $\mathrm{Ki}$ Dalang Seno Nugroho memainkan Wayang Limbuk. Di lain kesempatan penata sengaja datang di kediaman $\mathrm{Ki}$ Sutedjo untuk berkonsultasi dan meminta Ki Sutedjo untuk memainkan Wayang Limbuk yang kemudian diambil videonya untuk dijadikan acuan dalam proses pencarian gerak. Penata juga mencoba memain-mainkan wayang limbuk milik $\mathrm{Ki}$ Sutejo. Selanjutnya penata melakukan kerja studio sendiri untuk mencoba bergerak meniru seperti gerakan Wayang Limbuk. Pertemuan selanjutnya Penata memberi gambaran tentang sosok Limbuk kepada penari yang kemudian mengajak penari melakukan eksplorasi gerak di studio satu. Penata juga mengeksplor gerak putri gaya Yogyakarta khususnya ragam gerak encot, lilingan, serta gerak-gerak anggun, kemudian dikembangkan dengan pola ruang dan waktu. Hal tersebut dilakukan untuk menggambarkan seorang Bethari Kanastren tetapi memiliki satu ragam yang sama yang akan menjadi ciri khas saat menjadi Bethari maupun sudah menjadi Limbuk sesuai dengan interpretasi penata.
Saat menjadi Limbuk penata lebih mengembangkan motif kiprah sekaran gecul, merak ngigel, lilingan, dan encot . Gerakan tidak semata-mata gerak geculan melainkan efek dari eksplorasi gerakan tubuh yang memanfaatkan setiap bagian tubuh yang terlihat unik karena dilakukan dengan bentuk tubuh yang bahenol dengan perasaan yang selalu bangga terhadap dirinya sendiri. Penambahan bokongan dan payudara palsu dimaksudkan agar tubuh tampak bahenol yang juga dieksplor agar sesuai dengan teba gerak dan kenyamanan penari. Seluruh penari mengekspor bokongan dan payudara palsu serta eksplorasi gerakan sehari hari dalam merias diri dan memberikan arahan tentang menggunakan cermin, sisir dan kacu di stage hingga tidak ada kendala dalam mengeksplor properti tarinya.

Properti cermin, sisir, dan kacu diharapkan akan menghadirkan komposisi yang menarik, maka penata tari, penari dan penata artistik melakukan eksplorasi bersama sama baik di studio maupun diluar studio. Seluruh pendukung saling bertukar fikiran dan saling memberi saran dan masukan.

\section{b. Improvisasi.}

Improvisasi diartikan sebagai penemuan gerak secara kebetulan atau movement by chance, walaupun gerak-gerak tertentu muncul dari gerak-gerak yang pernah dipelajari atau ditemukan sebelumnya, tetapi ciri spontanitas menandai hadirnya tahap improvisasi (Y.Sumandiyo Hadi., Koreografi Bentuk-Teknik-Isi, Yogyakarta: Cipta Media, 2012, p. 77). Setelah eksplorasi dilakukan maka kerja studio terlebih dahulu dilakukan sendiri, kemudian dilakukan improvisasi berdasarkan konsep-konsep yang telah dipahami sebelumnya. Hasil dari improvisasi kemudian dijelajahi lagi sehingga menghasilkan kemungkinan-kemungkinan bentuk yang berbeda. Hal ini diterapkan kepada para penari juga, tidak menutup kemungkinan secara spontan ada penari yang menghasilkan gerak yang dirasa sesuai dengan apa yang diinginkan penata. Selanjutnya, 
gerak tersebut dicari lagi variasinya secara bersama-sama.

Pada tahapan ini, penari akan diberi kebebasan untuk bergerak dan berekspresi mengikuti instruksi dari penata tari. Pada tanggal 14 Oktober 2015 penata memberikan ilustrasi musik, sekelumit cerita tentang Limbuk, dan penata meminta penari merespon dengan melakukan improvisasi gerak. Melalui improvisasi, muncul gerak-gerak baru dari para penari dipilih yang dirasa sesuai yang kemudian akan disusun atau dikomposisikan ke dalam bentuk koreografi kelompok. Gerakgerak yang lebih ditekankan ialah pengembangan motif gerak putri yang dikembangkan menjadi lebar dan gerak-gerak keseharian tentang berhias yang telah distilisasi, yang tidak semata mata terfokus dengan gerak geculan, jika ada kesan gecul atau lucu dikarenakan efek dari eksplorasi gerak orang yang bertubuh bahenol.

\section{c. Penilaian (Evaluasi) Gerak}

Evaluasi dalam bahasa Inggris evaluation berarti proses penilaian. Penilaian terhadap hasil proses yang telah dilakukan meliputi eksplorasi dan improvisasi yang dirasa sesuai untuk digunakan, juga penilaian terhadap kemampuan penari dalam bergerak. Pada kenyataannnya, beberapa gerak yang telah dihasilkan melalui metode sebelumnya ada yang dirasa kurang sesuai jika dimasukkan ke dalam tatanan tari Gumrah Wewarah, seperti halnya permainan getaran di pantat dan payudara yang ternyata dapat menimbulkan arti yang sangat jauh menyimpang dari apa yang sebenarnya ingin disampaikan. Untuk itulah metode evaluasi menjadi sangat penting dan menentukan terciptanya suatu tatanan koreografi yang menarik dan sesuai dengan konsepnya.

Maksud lain dari evaluasi di sini adalah, penilaian atau koreksi dari penata mengenai proses yang sudah dilakukan para penari, penata music, serta semua pendukung yang terlibat di dalam garapan tari ini. Adapun halhal yang akan dievaluasi adalah aspek-aspek di dalam koreografi, seperti kualitas gerak penari, apakah gerak tersebut sesuai dengan tema garapan, apakah gerakannya bisa mewakili maksud apa yang hendak disampaikan, kemudian level, arah hadap, pola lantai, ruang, musik, serta semua yang berkaitan dengan jalannya proses latihan. Evaluasi di sini dimaksudkan untuk melihat kekurangankekurangan yang terdapat selama proses latihan agar dapat dibenahi secara terus menerus. Menambahkan hal-hal baru yang ditemukan selama proses latihan adalah salah satu cara yang dapat membantu proses perbaikan karya sampai mencapai hasil yang diinginkan.

\section{d. Komposisi}

Komposisi atau pengorganisasian bentuk merupakan akhir dari sebuah metode penciptaan tari. Setelah dilakukan penjelajahan konsep, eksperimen atau improvisasi gerak sesuai konsep, penilaian berikut pemilihan gerak maka dilakukan penyusunan, perangkaian atau penataan motif-motif atau frase-frase gerak hingga menjadi kalimat dan satu wacana koreografi yang utuh.

Dibutuhkan kecermatan, ketelitian, dan kreativitas yang tinggi dari penata untuk menyusun tiap bagian seperti gerak, pola lantai, ruang, volume,waktu dan interaksi dan komunikasi antar penari menjadi sebuah koreografi kelompok dan sesuai dengan ide garapan.

\section{Urutan Adegan}

Garapan ini merupakan karya tari yang terispirasi oleh tokoh Limbuk. Ekspresi gejolak hati tentang keteladanan Limbuk, baik saat sebagai Batari Kanestren yang merupakan sosok ibu Jagad yang baik hati dan pengasih sampai berubah ke wujud Limbuk sebagai pamong putri Nuswantara yang selalu sumringah dan jenaka. Pamomong yang selalu memberikan arahan, petuah serta tuntunan lewat pendekatan Kawruh (pengetahuan kasat mata), pendekatan ngelmu (pengetahuan tidak kasat mata) dan pendekatan ngelmi (pengetahuan yang bersumber dari religiusitas) yang bertujuan untuk menjadikan putri yang 
diemong menjadi putri yang Sekarjati (Bunga yang sejati) setiap kata yang terucap selalu disampaikan dengan mulut yang tersenyum (esem). (Daruni, "Limbuk Cangik sebagai Inspirasi Perancangan Koreografi Duet Sih Biyung”, dalam Resital Jurnal Seni Pertunjukan Volume 14 No. 2 - Desember, Yogyakarta: Fakultas Seni Pertunjukan Institut Seni Indonesia Yogyakarta, 2013, p.162)

Karya tari Gumrah Wewarah merupakan garapan dengan konsep koreografi kelompok. Menampilkan 8 penari dibagian awal, kemudian menampilkan 7 penari dibagian tengah dan menampilkan 8 penari di bagian akhir. Garapan ini terdiri dari lima bagian sebagai berikut :

\section{a. Introduksi}

Bagian awal ini menonjolkan sisi dramatik yang dibangun oleh delapan penari. Dramatisasi dalam bagian awal ini menampilkan penggambaran Wahyu Pradjana Paramitha yang dijaga oleh Bathari Kanestren yang nantinya akan diperuntukkan wanita terpilih yang akan menjadi seorang wanita yang sekarjati. Bagian ini tidak hanya sekedar gerak yang ditampilkan, melainkan menghadirkan musik yang memuat sulukan yang menggambarkan tentang tentang sosok wanita utama, syairnya yaitu Wanodya ayu utama, ngambar aruming kusuma, wadana anawang sasi, esemnya ngujiwat, lathinya manggis karengat, yen ngendika hesmu nggigit lathi, yang menciptakan suasana yang mistis namun agung. Suasana klasik juga sangat terlihat disini.

Ada dua penari yang on stage, satu penari di up left stage, dan satu penari lagi berada di down right stage. Kemudian Ada lima penari putri yang masuk ke stage melalui side wing satu kemudian melingkari seorang penari yang sudah berada di bagian down right stage dengan posisi level sedang. Setelah itu ketujuh penari bersama sama menari di dead center dan berjalan kembali ke down stage diakhiri pose kemudian black out.

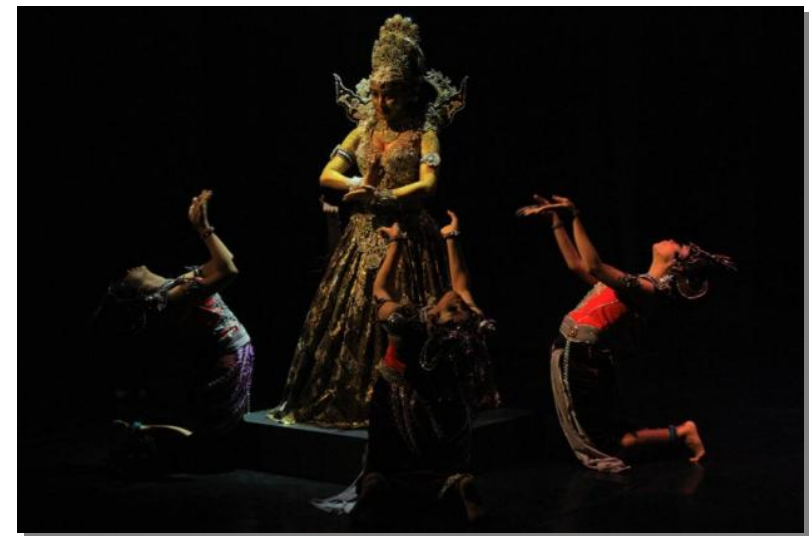

Gambar 1. Para Bhatari yang sedang menjagaWayu Pradja Paramitha (foto: Jhushinshu, 22 Januari 2016,

Pementasan Tugas Akhir di Auditorium Jurusan Tari, ISI Yogyakarta)

\section{b. Adegan 1}

Pada adegan satu, diawali dengan ketujuh penari putri memasuki stage secara bersama sama yang sedang menggambarkan suasana di Kahyangan dan keagungan Bathari Kanestren yang menjaga wahyu, mereka menari dengan anggun tetapi sesekali nampak energic sesuai dengan umurnya yang masih dikategorikan muda, permainan pola lantai dan level juga dihadirkan disini. Saat sedang asiknya menari kemudian muncul perintah Dewa untuk turun ke Arcapada mengemban tugas momong, ngamping ngampingi seorang putri yang akan mendapat wahyu putri yaknii wahyu Pradjna Paramitha, wahyu tersebut hanya untuk wanita yang terpilih yang nantinya akan menjadipemimpin dunia atau yang akan melahirkan seorang pemimpin besar.

Proses dari Kahyangan menuju Arcapada yang digambarkan melalui ketujuh penari menjadi satu garis membentuk diagonal di bagian up right stage kemudian black out dan hanya ada satu penari yang masih di stage, suasana berubah menjadi misterius dan tegang, selama tiga menit ia akan menari solo yang mengeksplor tubuhnya dengan berpegang pada konsep body isolation yang menceritakan transformasi Bathari Kanestren menjadi 
Limbuk dengan bentuk yang jenaka kemudian di akhiri Black out.

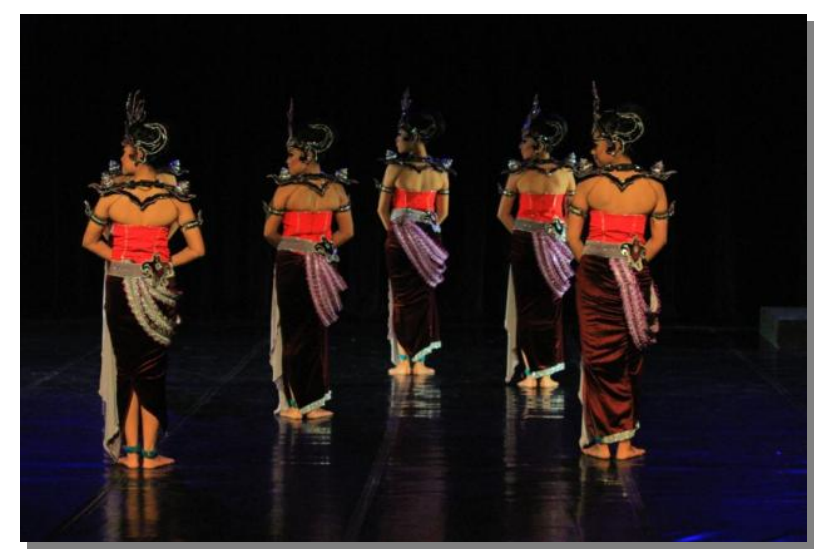

Gambar 2. Bhatari yang memperlihatkan keelokan dan kecantikannya (foto: Jhushinshu, 22 Januari 2016, Pementasan Tugas Akhir di Auditorium Jurusan Tari, ISI Yogyakarta)

\section{c. Adegan 2}

Adegan dua menceritakan sosok Limbuk yang sedang merasakan suasana baru hidup di Arcapada. Limbuk mulai beradaptasi dengan kehidupannya yang baru. Di awali dengan satu penari putri yang on stage di bagian up left stage yang sudah berkostum Limbuk, ia mengeksplor ruangan dari up left stage menuju up center kemudian berada di dead center.

Suasana yang hadir adalah suasana senang, bahagia, suka ria karena pada dasarnya ia menerima dan mengemban tugas tersebut dengan senang hati, didukung musik yang menggunakan vocal bersyair hem hem hem menambah suasana yang diinginkan tercapai. Kemudian ke enam penari masuk ke stage, dengan hadirnya ketujuh penari di stage, kemudian menggunakan permainan pola hitungan dan ruang yang sangat beragam, ditambah lagi tempo gerak yang sangat dinamis dan sistem entrance-exit yang sulit ditebak. Gerakan yang disuguhkan adalah gerak hasil eksplorasi dari tubuh Limbuk yang unik sehingga teba gerak yang didapat juga unik.

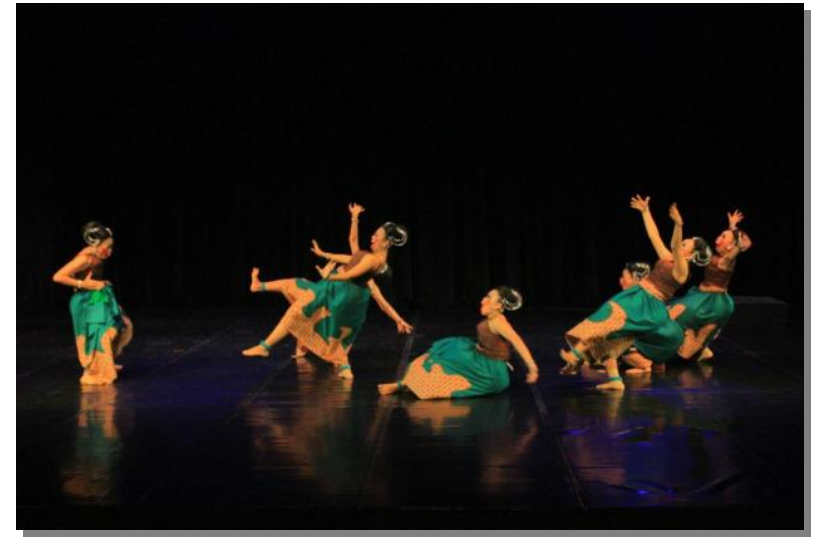

Gambar 3. Kegembiraan Limbuk yang sedang bersenda gurau

(foto: Jhushinshu, 22 Januari 2016, Pementasan Tugas Akhir di Auditorium Jurusan Tari, ISI Yogyakarta)

\section{d. Adegan 3}

Adegan dua menceritakan Limbuk mulai melaksanakan tugasnya sebagai Jurudan atatu Juru dandan, Juru sisir, Jurubah atau Juru tebah. Pada adegan ini permainan properti seperti cermin, sisir dan kacu pun dihadirkan dan dieksplor sedemikian rupa, properti tersebut memiliki arti Filosofi masingmasing. Aktivitas Limbuk yang selalu membawa dan memainkan sisir, cermin dan kacu yang dipergunakan untuk momong putri kelak akan dijadikan putri Sekarjati. Properti yang dibawa Limbuk tersebut yang kemudian dieksplor menjadi properti tari.

Dua penari keluar stage dan masih ada lima penari yang on stage, adegan ini ditarikan oleh lima penari putri, dua penari berada di bagian up left stage, dua penari lagi berada di up right stage dan satu penari berada di down left stage. Suasana yang hadir pada adegan ini adalah sakral, serius karena pada adegan ini Limbuk memberikan wewarah tentang bagaimana menjadi wanita yang sekarjati wanita utama. 


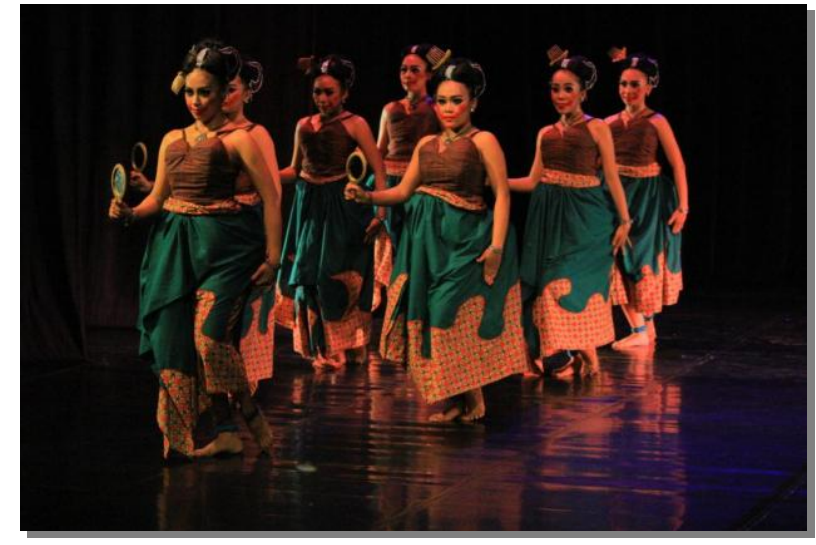

Gambar 4. Menjemput Wahyu Pradjna Paramitha

(foto: Jhushinshu, 22 Januari 2016,

Pementasan Tugas Akhir di Auditorium Jurusan Tari, ISI Yogyakarta)

\section{e. Ending}

Pada bagian ending akan menampilkan perintah Wahyu Pradjna Paramitha yakni wahyu yang diperuntukan seorang putri yang terpilih menjadi perempuan nuswantara yang sejati segera diturunkan kepada sosok wanita yang terpilih, dan wahyu tersebut dikawal oleh Limbuk dan Cangik. Ketujuh penari bergegas menata barisan dan segera menjemput satu wanita yang ditunjuk sebagai gambaran Wahyu Pradjna Paramitha yang berjalan dari Laut Selatan yang penuh dengan cahaya emas, yang berjalan diatas trap memanjang dari Backdrop menuju Up Center. Kedua penari berjalan menjemput Wahyu sebagai gambaran Limbuk dan Cangik, sedangkan penari yang lainnya duduk dalam pose berdoa.

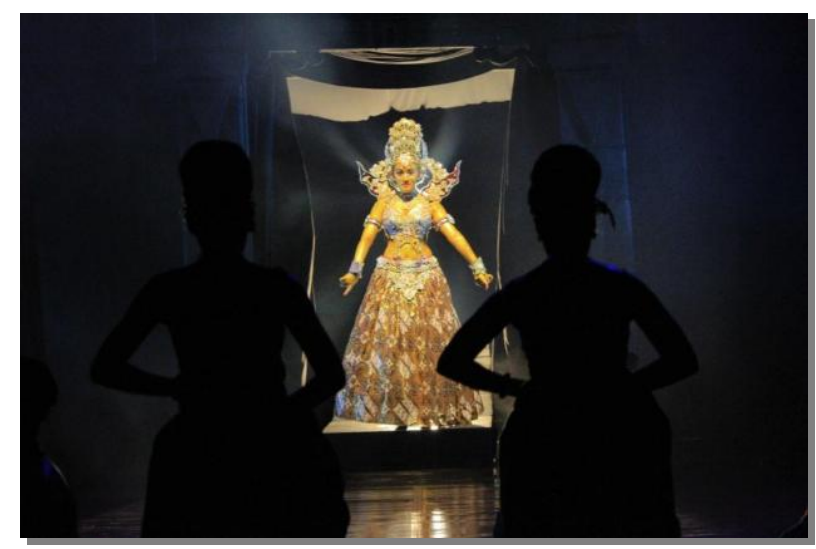

Gambar 5. Perwujudan Wahyu Pradja Paramitha

(foto: Jhushinshu, 22 Januari 2016,

Pementasan Tugas Akhir di Auditorium Jurusan Tari, ISI Yogyakarta)

\section{Kesimpulan}

Ketertarikan terhadap figure Wayang Limbuk, mendorong diciptakannya karya tari berjudul Gumrah Wewarah. Gumrah memiliki arti ramai, keramaian, dan bercanda yang berkonotasi positif, Wewarah memiliki arti nasehat. Gumrah Wewarah memiliki arti seorang Bathari Kanestren yang telah berubah wujud menjadi Limbuk yang jenaka, ia selalu memberikan suasana yang bahagia, sumringah, ramai dan selalu jenaka, memiliki tujuan agar yang di momong betah, remaket dan bahagia namun dibalik itu semua ada nasehat yang tersirat di dalamnya. Mulut Limbuk yang mengucap dan mengurai sebuah makna tentang kesejatian perempuan nuswantara yang terpilih, dan semua ucapan dan uraian itu selalu disampaikan lewat mulut yang tersenyum.

Limbuk bukan sekedar abdi dalem, tetapi juga pamomong yang masih tergolong masih remaja berkarakter genit namun selalu memberikan tuntunan dan memuat wewarah didalam kejenakaannya, tidak pernah lepas dari cermin, sisir dan kacu yang selalu ia bawa, baik untuk menghias dirinya sendiri ataupun mendandani para putri yang di emong nya, Limbuk memiliki tugas untuk mendidik putri tersebut agar menjadi putri yang Sekarjati.

Karya tari divisualisasikan dalam bentuk tari kelompok, didukung oleh tujuh penari putri, dan dipentaskandi proscenium stage. Pijakan pengembangan gerak berasal dari gerak tari putri gaya yogyakarta dan motif gerak kiprah sekaran gecul, merak ngigel, lilingan, dan encot.

\section{Saran dan Masukan}

Seorang penari atau penata tari memiliki perbedaan dengan orang pada 
umumnya. Disaat semua orang bisa berbicara dengan mulut dan lidahnya, penata tari atau pun penari bisa menyampaikan sesuatu atau berkomunikasi dengan gerak-gerak yang dilakukan oleh tubuh dan ditata hingga menjadi satu kesatuan yang utuh. Berkarya merupakan sebuah sarana yang paling ideal untuk mencurahkan apa yang dirasakan oleh seseorang. Karya tercipta lewat gagasan yang sebelumnya muncul dalam hati dan fikiran manusia.

Gagasan ini kemudian diterjemahkan kedalam konsep dan direalisasikan kedalam bentuk tari. Banyak hal yang dilalui dalam proses penuangan ide ke dalam bentuk tari. Segala kemungkinan terbaik dan terburuk mungkin akan dilewati seperti sulitnya mencari penari dengan jumlah dan kriteria yang diinginkan, mengatur penari yang jumlahnya terbilang cukup banyak, kendala pada pendanaan proses penciptaan, penggabungan beberapa elemen seni pertunjukan seperti tari, musik, setting, pencahayaan dan lain-lain.

Apabila sanggup melalui segala kemungkinan buruk tersebut maka terlahir lah karya yang spektakuler dan memuaskan. Selain itu, Manfaat bagi penata, yaitu penata mengetahui perbedaan antara pamomong dan abdi dalem, keluhuran serta keteladanan pamomong. Penata menjadi bisa menghadapi beberapa watak dan karakter dari masingmasing penari. Belajar tidak menilai seseorang dari penampilan luarnya saja. Belajar memanagemen diri seperti membagi waktu. Sadar akan pentingnya sosok perempuan sehingga menata diri sedemikian rupa agar menjadi wanita yang sekarjati. Serta tersampaikan pula niat hati untuk ikut membantu menjaga kelestarian budaya Jawa dan rasa hormat untuk para Leluhur dan para sosok pamomong.

Setelah melalui proses selama tiga bulan lamanya, sehingga telah melewati fase olah gerak serta olah rasa. Visi untuk pencitraan image Limbuk yang bukan sekedar abdi dalem atau mbok emban, namun yang sebenarnya adalah sebagai pamomong.
Menciptakan sebuah karya yang bukan sekedar tontonan hiburan namun tontonan yang memuat tuntunan.

Rasa syukur kepada Allah SWT yang telah memberikan nikmat kesehatan sehingga proses penggarapan karya tari ini dapar berjalan dengan baik. Ucapan terimakasih kepada seluruh pendukung karya tari ini yang telah memberikan banyak pengalaman. Proses penciptaan karya tari ini diyakini masih banyak memiliki kekurangan, terlebih setelah dihadapkan pada pola tindak kreatif di lapangan maupun studio, karena semua yang disampaikan penata baru bersifat konseptual, artinya masih dalam ranah pemikiran. Untuk itu penata mengharapkan kritik dan saran sebagai bahan perenungan dan perbaikan.

\section{SUMBER ACUAN}

\section{a. Sumber Tercetak}

Daruni. 2013. "Limbuk Cangik sebagai Inspirasi Perancangan Koreografi Duet Sih Biyung", dalam Resital Jurnal Seni Pertunjukan Volume 14 No. 2 Desember. Yogyakarta: Fakultas Seni Pertunjukan Institut Seni Indonesia Yogyakarta.

Hadi, Y. Sumandiyo. 2012. Koreografi Bentuk-Teknik-Isi. Yogyakarta: Cipta Media.

Hartadi, Timmy dan Agung Bimo Sutedjo. 2009. Jagad Gumelar. Tatanan Jagad Raya. Yogyakarta: Turanggaseta.

Wangi, Sena. 1999. Ensiklopedi Wayang Indonesia 1. Jakarta: Sena Wangi.

.1999. Ensiklopedi Wayang Indonesia 4. Jakarta: Sena Wangi. 


\section{b. Sumber Lisan}

1. Nama : Mas Panewu Cermo Sutedjo

Umur : 57 Tahun

Pekerjaan : Dalang

2. Nama : Timmy Hartadi

Umur : 48 Tahun

Pekerjaan : Spiritualis 